\title{
Therapeutic Targets in Breast Cancer Stem Cells
}

\author{
Alfredo Amador-Molina1, S. Mayra Pérez-Tapia² and Marco A. Velasco-Velázquez ${ }^{3 *}$ \\ ${ }^{1}$ Unidad de Investigación Biomédica en Cáncer, Instituto Nacional de Cancerología, México D.F., México \\ ${ }^{2}$ Departamento de Inmunología, Escuela Nacional de Ciencias Biológicas, Instituto Politécnico Nacional. México D.F., México \\ ${ }^{3}$ Departamento de Farmacología, Facultad de Medicina, Universidad Nacional Autónoma de México. Apdo. Postal 70-297, Ciudad Universitaria, México D.F. 04510, \\ México
}

\begin{abstract}
Breast cancer stem cells (BCSCs) constitute a subpopulation of tumor cells with self-renewal capability, expression of stem cell-like markers, and increased tumorigenicity in vivo. Clinical evidence has shown that BCSCs play a major role in the initiation, maintenance, and outcome of breast tumors. Therefore, BCSCs have been identified as ideal targets for the development of new therapies. Such therapies must consider the phenotypical differences between BCSCs cells, non-stem tumor cells, and normal cells. This review summarizes different strategies for BCSCs eradication that have been employed in preclinical assays, including: i) targeting proteins differentially expressed such as surface markers, transporters, or enzymes; ii) inhibiting self-renewal pathways; and iii) blocking the interaction of the BCSCs with their niche. These approaches may become the basis for the generation of effective and clinically applicable therapies that prevent disease relapse, metastasis, and enhance patient survival.
\end{abstract}

Keywords: Breast cancer stem cells; Breast cancer therapy; Niche; Metformin

\section{Introduction}

Breast cancer causes more than 410,000 women's deaths worldwide each year [1-4]. The number of new breast cancer cases per year has steadily increased in the last 20 years, especially in low and middle income countries [5]. Despite advances in the diagnosis, classification, and therapeutics it is expected that mortality rate will increase in the following years caused by population increment, longer life-spans and increased exposure to environmental risks [6].

Current alternatives for breast cancer therapy include cytotoxic, hormonal, and immunotherapeutic agents. In general, first-line therapy produces responses in $60 \%$ to $80 \%$ of primary tumors $[7,8]$ but is effective only for a short period of time [9]. As consequence, up to $70 \%$ of patients show recurrent and/or metastatic disease within 5 years [9-11]. These data indicate the need of new approaches for breast cancer treatment. Such approaches must consider the role of breast cancer stem cells (BCSCs) in the initiation, maintenance, and clinical outcome of breast cancers.

Al-Hajj and collaborators [12] achieved the discovery of a subpopulation of cancer stem cells (CSCs) in human breast tumors almost a decade ago. They have identified a cellular population characterized by cell-surface CD $44^{+} / \mathrm{CD} 24^{- \text {/low }} /$ Epithelial cell Surface Antigen $^{+}\left(\mathrm{ESA}^{+}\right)$markers, and lineage- (lack of expression of CD2, CD3, CD10, CD 16, CD18, CD31, CD64, and CD140b) that was highly tumorigenic [12]. As few as 200 of these cells generated tumors when xenotransplanted into nonobese diabetic-severe combined immunodeficient (NOD-SCID) mice while tens of thousands of other cancer cells could not [12]. Further characterization has shown that BCSCs [13]: i) express specific markers that allow their identification/ isolation; ii) express genes and display activated cell signaling pathways associated with normal stem cells; iii) are able to self-renew; and iv) can differentiate to the heterogeneous phenotypes that compromises tumors.

\section{Targeting BCSCs}

The molecular and phenotypic differences between BCSCs and nonstem tumor cells are reflected in differences in sensibility to radiation and chemotherapy. At present, it is accepted that BCSCs display increased resistance to therapy. For example, cancer cells isolated from patients who received chemotherapy have increased in vitro selfrenewing capability and augmented proportion of BCSCs compared with cells isolated from chemotherapy-naive patients [14,15]. Similarly, radiation therapy increases the proportion of $\mathrm{CD} 44^{+} / \mathrm{CD} 24^{-/ \mathrm{low}}$ cells in mouse xenografts $[16,17]$. Thus, therapy increases the fraction of BCSCs cells by eliciting a selective pressure and/or preventing their differentiation. Furthermore, the resistance to therapy can be inherited from BCSCs to progenitor cells and then to the non-stem tumor cells, as reported by Shafee et al. [18]. Therefore, the expansion of the CSC population after therapy may be directly related to the appearance of clinical resistance.

Because of their intrinsic characteristics and their clinical relevance, new therapies for breast cancer should pursue the eradication of the BCSC pool with no harm to other cell types. At least three different strategies have developed to achieve this goal (Figure 1). First, BCSCs can be targeted using differentially expressed proteins, like surface markers, transporters, or enzymes. Secondly, BCSC expansion can be limited by inhibiting the pathways involved in self-renewal. Finally, given that BCSCs require specific microenvironments, targeting their interactions with the niche may be beneficial. These strategies will be discussed further below.

\section{Targeting of differentially expressed markers}

BCSCs overexpress ATP-Binding Cassette (ABC) transporters

*Corresponding author: Marco A. Velasco-Velázquez, Departamento de Farmacología, Facultad de Medicina, UNAM, Apdo. Postal 70-297, Ciudad Universitaria. México D.F. 04510, México, Tel: + (52-55) 5623-2282; Fax: + (52-55) 5616-1489; E-mail: marcovelasco@unam.mx

Received May 22, 2012; Accepted August 01, 2012; Published August 03, 2012

Citation: Amador-Molina A, Pérez-Tapia SM, Velasco-Velázquez MA (2012) Therapeutic Targets in Breast Cancer Stem Cells. J Mol Biomarkers Diagn S8:005. doi:10.4172/2155-9929.S8-005

Copyright: (C) 2012 Amador-Molina A, et al. This is an open-access article distributed under the terms of the Creative Commons Attribution License, which permits unrestricted use, distribution, and reproduction in any medium, provided the original author and source are credited 


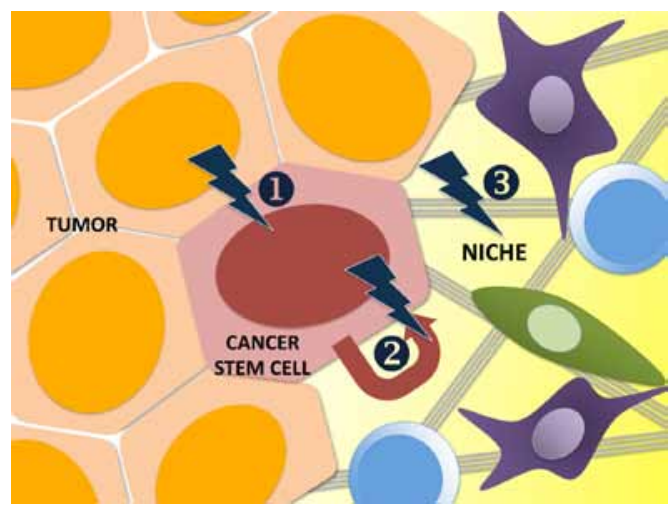

Figure 1: Therapeutic targets in breast cancer stem cells. Three different strategies have been identified for the eradication of BCSCs. (1) The subpopulation of BCSCs can be reduced by targeting proteins differentially expressed in those cells, such as surface markers, transporters, or enzymes. (2) The expansion of BCSCs in tumors can be limited by inhibiting the pathways that control self-renewal (pictured as a self-pointing arrow), such as Notch Hedgehog, PTEN, Wnt, NF-kB, or BMI-1. (3) Survival, proliferation, and/ or differentiation of BCSCs can be affected by blocking their interaction with normal cells (pictured on the far right) or extracellular matrix at their primary or metastatic niches.

like P-glycoprotein (P-gp or MDR1), multiple resistance-associated protein-1 (MRP1), breast cancer resistance protein (BCRP), and ABC sub-family $\mathrm{G}$ member 2 (ABCG2) [19-21]. The expression of these and other $\mathrm{ABC}$ transporters partially explains why chemotherapy is ineffective in eradicating BCSCs. For example, ABCG2 is overexpressed in a subpopulation of breast tumor cells with stem-cell properties [21] but its expression and the ability to efflux drugs is lost during differentiation of BCSCs to non-stem cancer cells [14].

The use of inhibitors of $\mathrm{ABC}$ transporters simultaneously with anticancer drugs is an efficient approach to overcome resistance in vitro and in animal models [22]. Thus, several inhibitors of ABC-transporters have been identified and some of them have been evaluated in breast cancer models. Different secondary metabolites from plants modify the activity of $\mathrm{ABC}$ transporters. For example, jatrophane diterpenoids isolated from Euphorbia species inhibit ABC transporters and sensitize mouse lymphoma cells to chemotherapy [23]. Similarly, the plant alkaloids thaliblastine and berberine reverse multi-drug resistance in breast cancer cells by decreasing the expression of P-gp and ABCG2, respectively $[24,25]$. Even when the effect of these plant metabolites on BCSCs has not been evaluated, they could be useful in the eradication of BCSC pools due to their mechanism of action [20]. However, the ability to target drug transport in BCSCs may be difficult since these cancer cells express multiple $A B C$ transporters [26]. Furthermore, since $\mathrm{ABC}$-transporters are also expressed in normal stem cells, there is a high risk of serious side effects [22,27].

A different approach for targeting BCSCs is based on the differential expression of specific surface markers that can be identified with antibodies. This strategy has proven to be partially successful in acute myeloid leukemia (AML) [28,29]. Likewise, anti-CD44 antibodies conjugated with cytotoxic drugs or radiolabels have shown to reduce disease progression in breast cancer patients and animal models [30]. Similarly, a humanized anti-CD44 antibody reduces effectively tumor growth in pancreatic cancer xenografts [31]. Different anti-ESA antibodies are effective in preclinical models of colon and prostate cancer $[32,33]$, suggesting that they may have activity in breast tumors where ESA is a BCSC marker. Agonist antibodies against death receptors also have shown activity against BCSCs; immunotherapy with anti-Fas or anti-DR5 induces apoptosis efficiently in mammary BCSCs [34].

In conjunction, these data suggest that the use of antibodies can be a good approach for BCSCs eradication. However, immunotherapy has some limitations: BCSCs are typically present at low numbers within tumors, which can complicate the interaction of antibodies with the target cells. In addition, BCSC markers can overlap with normal stem cells, which may lead to serious adverse effects. In other to improve the selectivity and efficacy of immunotherapies that target CSCs, it has been suggested the combined use of two antibodies with two different targets, but such strategy would require extensive optimization.

\section{Targeting of self-renewal pathways}

BCSCs have the ability to self-renew. The molecular pathways involved in this process are similar to those that control self-renewal in normal stem cells. In BCSCs, the Notch, Hedgehog, PTEN, Wnt, NF- $\kappa B$, and BMI-1 pathways have been implicated in self-renewal [35] Even when the clarification of the role of each self-renewal pathway in maintaining BCSCs remains to be determined, BCSC pool may be reduced by targeting these pathways. For example, the PTEN/PI3-K/ Akt/Wnt/ $\beta$-catenin pathway is active in BCSCs. PTEN knockdown in human breast cancer cell lines induced activation of Akt, increased in vitro self-renewal, and increased the BCSC population [36]. Active Akt phosphorylates GSK3 $\beta$ and thereby the Wnt pathway. Ongoing autocrine signaling via the Wnt pathway has been shown to regulate and maintain BCSC self-renewal [37]. PKF 118-310 is an inhibitor of Wnt pathway that is able to decrease self-renewal of mammary epithelial stem/progenitor cells in vitro, and blocks tumor growth in mouse models [38].

The Notch receptors and their ligands participate in a conserved mechanism that can regulate cell fate determination $[39,40]$. Notch receptor activation depends on its interaction with ligands from the Delta and Serrate/Jagged families. Following ligand binding, Notch receptors are sequentially cleaved by a metalloprotease and $\gamma$-secretase [40]. These steps lead to the release of the Notch intracellular domain (NICD) into the cytoplasm, which in turn translocates into the nucleus to activate target genes such as HES, HEY and c-Myc [40,41] Elevated levels of Notch1 and Jagged1 mRNA are associated with poor prognosis in human breast cancer $[42,43]$. Therefore, Notch-activated signaling has being identified as a therapeutic target in breast and other cancer types [44]. Accordingly, a $\gamma$-secretase inhibitor and a Notch-4 neutralizing antibody inhibit in vitro self-renewal in breast cancer cells [43]. Furthermore, Notch inhibition induces apoptosis in breast cancer cells but not in normal breast epithelial cells, although self-renewing was also blocked in normal cells [43]. These results indicate that drugs designed to target Notch signaling may be effective to block self-renewal of BCSCs. However, preclinical studies of $\gamma$-secretase inhibitors have shown that they produce organ-specific toxicity [45], suggesting that further work is needed to identify the role of specific Notch receptors in BCSC biology as well as selective inhibitors for each of them.

\section{Targeting the niche}

The CSCs require a highly specific and discrete microenvironment (niche) just as normal stem cells. The function of the niche is to provide a physical anchoring site for CSCs via adhesion molecules and supply extrinsic factors [46]. It has been hypothesized that the survival, proliferation, and/or differentiation of BCSCs can be activated by signals from the niche [46-48]. Thus, the niche can promote BCSC 
expansion or the acquisition of stem cell-like properties. Additionally, the microenvironment is a critical regulator of BCSC-driven metastasis. Signals from the extracellular matrix (ECM) or stromal cells can act as chemo attractants or can regulate the dormancy at metastatic sites (reviewed by [49]).

Interaction of hyaluronic acid (HA) with its receptor CD44 in breast carcinoma cells causes the recruitment of Nanog into the CD44-HA complex which supports the expression of pluripotent stem cell regulators such as Rex1 and Sox2 [50]. Additionally, the CD44HA pathway may be important in therapeutic resistance, since HAtreatment of breast cancer cells reduces intracellular retention of cytotoxic drugs and promotes multidrug resistance [50]. Inhibiting HA synthesis using the drug 4-methylumbelliferone (4-MU) enhanced trastuzumab (an anti-HER2 antibody) effectiveness [51]. Antibodies specific for the HA-binding interface have been developed to target the CD44-HA interaction [52]. Similarly, the a6 integrin (CD49f), a subunit of a laminin receptor, is necessary for survival and/or proliferation of BCSCs. The expression of the $a 6$ integrin subunit increases with serial passages of mammospheres generated from individual breast cancer cells [53]. Inhibition of a6 integrin, using antibodies or siRNA, induces the complete loss of mammosphere-forming ability and inhibits tumorigenicity in vivo [53]. These data indicate that adhesion receptors containing the $a 6$ integrin subunit may be suitable targets to block tumor growth in breast cancer.

Beside ECM components, the niche has different types of cells that secrete a complex mixture of soluble factors that promote BCSC expansion/survival. For example, the cytokine IL-8 and the chemokine CCL5 can be secreted by breast cancer cells [54] and normal mesenchymal stem cells [55], respectively. Interestingly, the secretion of CCL5 from mesenchymal stem cells is dependent on the presence of breast cancer cells [55] indicating that the interaction between cancer cells and their niche is reciprocal. The therapeutic importance of blocking soluble signals generated at the niche in BCSC eradication has been highlighted by the evaluation of cytokine-receptor antagonists. The anti-inflammatory drug repertaxin, an antagonist of the IL- 8 receptor CXCR1, reduced the BCSC population, producing apoptosis in the non-stem tumor population and reducing metastasis formation in mouse models [56]. These results suggest that other receptors involved in BCSC biology can be targeted, either with antagonists or with interference RNA.

\section{Other targets}

Some drugs developed and tested for other therapeutic applications, such as salinomycin and metformin, have shown activity against breast CSCs. Their mechanism of action is still unclear and/ or may involve multiple pathways. The ionophore salinomycin was identified as toxic to BCSCs by high-throughput screening [57] and is effective killing gastric CSCs [58]. Treatment of mammosphere cultures with salinomycin reduces the expression of the stem cell marker SOX2, indicating a reduction in the proportion of cells with the BCSC phenotype [59]. The combined treatment with salinomycin and trastuzumab enhances therapy effectiveness [59]. Salinomycin is also capable of inducing apoptosis in human cancer cells of different origins that display multiple mechanisms of drug resistance $[60,61]$ and sensitize breast cancer cell to antimitotic microtubule-targeting drugs [62]. Although the precise way of action of salinomycin remains to be determined, there is evidence that salinomycin induces a conformational change of the $\mathrm{ABC}$ transporter MDR1/ABCB1 that reduces its activity [63] and increases DNA damage and promotes cell cycle arrest in antimitotic drug-treated cancer cells [62].
The anti-diabetic drug metformin has been used in treatments in breast cancer due its ability to preferentially kill BCSCs. Metformin has a higher cytotoxic effect in BCSCs over no-stem tumor cells $[64,65]$. The combination of metformin with trastuzumab removes stem cell population and suppresses proliferation and renewal of BCSC HER2 carcinomas [66]. In a xenograft mouse model, concurrent treatment with metformin and chemotherapeutic agents reduced tumor mass more effectively than either drug alone and prevents relapse [64]. Metformin has also been used with ionizing radiation, and this combination improves the effect of radiotherapy over BCSCs in vitro [65]. A similar effect was observed in vivo, where metformin enhanced tumor growth inhibition by radiotherapy [65]. Despite the increasing number of studies that analyze the effects of metformin in breast cancer cells, the mechanisms involved are not yet entirely clear. Metformin exerts (at least in part) its effects by activating the AMP-activated kinase (AMPK) pathway, which drives to mTOR inactivation. These effects correlate with cell arrest, apoptosis, and inhibition of tumorigenesis [67-69]. AMPK activation can also lead to the inhibition of Acetyl CoA carboxylase (ACACA) affecting fatty acid synthesis. Thus, another possible mechanism of metformin may be the alteration of lipid rafts functions.

\section{Conclusions and Perspectives}

BCSCs have a central role in breast cancer progression since they are involved in tumorigenesis, therapy response, and metastasis formation. Thus, new therapies that target these cells are urgently required. Those therapies could be a better approach to avoid the refractory nature of breast cancer to conventional therapy. The development of such therapies must consider the phenotypical differences between BCSCs cells and the rest of the tumor cells. Surface markers, transporters, enzymes, and signal transducers differentially expressed are ideal candidates. On the other hand, the design of new therapies must also take in consideration which pathways are shared between BCSCs and normal stem cells in order to reduce the possible toxic effects. Therefore, the following are still essential: i) the characterization of new biomarkers for BCSC; ii) the elucidation of the specific mechanisms by which BCSCs survive chemotherapy, regulate self-renewal, and interact with their primary and metastatic niches; and iii) the clarification of the relationship between the presence of BCSCs and clinical progression. Such approaches may become the basis for the generation of effective and clinically applicable therapies that prevent disease relapse, metastasis, and enhance patient survival.

\section{Acknowledgements}

This research work was supported in part by UNAM, "Proyecto Factor de Transferencia", IPN, and a grant from "Instituto Científico Pfizer México".

\section{References}

1. Parkin DM, Bray F, Ferlay J, Pisani P (2005) Global cancer statistics, 2002. CA Cancer J Clin 55: 74-108.

2. Parkin DM, Fernandez LM (2006) Use of statistics to assess the global burden of breast cancer. Breast J 12: S70-80.

3. Anderson BO, Yip CH, Ramsey SD, Bengoa R, Braun S, et al. (2006) Breas cancer in limited-resource countries: health care systems and public policy. Breast J 12: S54-69.

4. Ferlay J, Shin HR, Bray F, Forman D, Mathers C, et al. (2010) Estimates of worldwide burden of cancer in 2008: GLOBOCAN 2008. Int J Cancer 127 2893-2917.

5. Pedraza AM, Pollan M, Pastor-Barriuso R, Cabanes A (2012) Disparities in breast cancer mortality trends in a middle income country. Breast Cancer Res Treat 134: 1199-1207. 
6. Bray F, Moller B (2006) Predicting the future burden of cancer. Nat Rev Cancer 6: 63-74

7. Guarneri V, Conte PF (2004) The curability of breast cancer and the treatment of advanced disease. Eur J Nucl Med Mol Imaging 31: S149-161.

8. Gonzalez-Angulo AM, Morales-Vasquez F, Hortobagyi GN (2007) Overview of resistance to systemic therapy in patients with breast cancer. Adv Exp Med Biol 608: 1-22

9. Pusztai L, Hortobagyi GN (1998) High-dose chemotherapy: how resistant is breast cancer? Drug Resist Updat 1: 62-72.

10. Pisani P, Bray F, Parkin DM (2002) Estimates of the world-wide prevalence of cancer for 25 sites in the adult population. Int J Cancer 97: 72-81.

11. Colleoni M, Viale G, Zahrieh D, Pruneri G, Gentilini O, et al. (2004) Chemotherapy is more effective in patients with breast cancer not expressing steroid hormone receptors: a study of preoperative treatment. Clin Cancer Res 10: $6622-6628$.

12. Al-Hajj M, Wicha MS, Benito-Hernandez A, Morrison SJ, Clarke MF (2003) Prospective identification of tumorigenic breast cancer cells. Proc Natl Acad Sci USA 100: 3983-3988.

13. Velasco-Velazquez MA, Homsi N, De La Fuente M, Pestell RG (2012) Breas cancer stem cells. Int J Biochem Cell Biol 44: 573-577.

14. Yu F, Yao H, Zhu $P$, Zhang $X$, Pan Q, et al. (2007) let-7 regulates self renewal and tumorigenicity of breast cancer cells. Cell 131: 1109-1123.

15. Tanei T, Morimoto K, Shimazu K, Kim SJ, Tanji Y, et al. (2009) Association of breast cancer stem cells identified by aldehyde dehydrogenase 1 expression with resistance to sequential Paclitaxel and epirubicin-based chemotherapy for breast cancers. Clin Cancer Res 15: 4234-4241.

16. Zielske SP, Spalding AC, Wicha MS, Lawrence TS (2011) Ablation of breast cancer stem cells with radiation. Transl Oncol 4: 227-233.

17. Phillips TM, McBride WH, Pajonk F (2006) The response of CD24(-/low)/CD44+ breast cancer-initiating cells to radiation. J Natl Cancer Inst 98: 1777-1785

18. Shafee N, Smith CR, Wei S, Kim Y, Mills GB, et al. (2008) Cancer stem cells contribute to cisplatin resistance in Brca1/p53-mediated mouse mammary tumors. Cancer Res 68: 3243-3250.

19. Loo TW, Clarke DM (2005) Recent progress in understanding the mechanism of P-glycoprotein-mediated drug efflux. J Membr Biol 206: 173-185.

20. Wink M, Ashour ML, El-Readi MZ (2012) Secondary Metabolites from Plants Inhibiting ABC Transporters and Reversing Resistance of Cancer Cells and Microbes to Cytotoxic and Antimicrobial Agents. Front Microbiol 3: 130.

21. Christgen $M$, Ballmaier $M$, Bruchhardt $H$, von Wasielewski $R$, Kreipe $H$, et al. (2007) Identification of a distinct side population of cancer cells in the Cal-51 human breast carcinoma cell line. Mol Cell Biochem 306: 201-212.

22. Ozben T (2006) Mechanisms and strategies to overcome multiple drug resistance in cancer. FEBS Lett 580: 2903-2909.

23. Hohmann J, Molnar J, Redei D, Evanics F, Forgo P, et al. (2002) Discovery and biological evaluation of a new family of potent modulators of multidrug resistance: reversal of multidrug resistance of mouse lymphoma cells by new natural jatrophane diterpenoids isolated from Euphorbia species. J Med Chem 45: $2425-2431$

24. Chen G, Teicher BA, Frei E, 3rd (1996) Differential interactions of Pgp inhibitor thaliblastine with adriamycin, etoposide, taxol and anthrapyrazole Cl941 in sensitive and multidrug-resistant human MCF-7 breast cancer cells. Anticancer Res 16: 3499-3505.

25. Kim JB, Ko E, Han W, Shin I, Park SY, et al. (2008) Berberine Diminishes the Side Population and ABCG2 Transporter Expression in MCF-7 Breast Cancer Cells. Planta Med 74: 1693-1700.

26. de Grouw EP, Raaijmakers $\mathrm{MH}$, Boezeman JB, van der Reijden BA, van de Locht LT, et al. (2006) Preferential expression of a high number of ATP binding cassette transporters in both normal and leukemic CD34+CD38- cells. Leukemia 20: 750-754.

27. Lou H, Dean M (2007) Targeted therapy for cancer stem cells: the patched pathway and ABC transporters. Oncogene 26: 1357-1360.

28. Tsimberidou AM, Giles FJ, Estey E, O'Brien S, Keating MJ, et al. (2006) The role of gemtuzumab ozogamicin in acute leukaemia therapy. $\mathrm{Br} \mathrm{J}$ Haemato 132: 398-409.
29. Sperr WR, Florian S, Hauswirth AW, Valent P (2005) CD 33 as a target of therapy in acute myeloid leukemia: current status and future perspectives. Leuk Lymphoma 46: 1115-1120.

30. Platt VM, Szoka FC, Jr. (2008) Anticancer therapeutics: targeting macromolecules and nanocarriers to hyaluronan or CD44, a hyaluronan receptor. Mol Pharm 5: 474-486.

31. Young D (2007) Arius Research. Patent WO2007098571.

32. Ammons WS, Bauer RJ, Horwitz AH, Chen ZJ, Bautista E, et al. (2003) In vitro and in vivo pharmacology and pharmacokinetics of a human engineered monoclonal antibody to epithelial cell adhesion molecule. Neoplasia 5: 146154.

33. Naundorf S, Preithner S, Mayer P, Lippold S, Wolf A, et al. (2002) In vitro and in vivo activity of MT201, a fully human monoclonal antibody for pancarcinoma treatment. Int J Cancer 100: 101-110.

34. Li M, Knight DA, Smyth MJ, Stewart TJ (2012) Sensitivity of a novel model of mammary cancer stem cell-like cells to TNF-related death pathways. Cancer Immunol Immunother.

35. O'Brien CA, Kreso A, Jamieson CH (2010) Cancer stem cells and self-renewal. Clin Cancer Res 16: 3113-3120.

36. Korkaya H, Paulson A, Charafe-Jauffret E, Ginestier C, Brown M, et al. (2009) Regulation of mammary stem/progenitor cells by PTEN/Akt/beta-catenin signaling. PLoS Biol 7: e1000121

37. Scheel C, Eaton EN, Li SH, Chaffer CL, Reinhardt F, et al. (2011) Paracrine and autocrine signals induce and maintain mesenchymal and stem cell states in the breast. Cell 145: 926-940.

38. Hallett RM, Kondratyev MK, Giacomelli AO, Nixon AM, Girgis-Gabardo A, et al (2012) Small molecule antagonists of the Wnt/beta-catenin signaling pathway target breast tumor-initiating cells in a Her2/Neu mouse model of breast cancer. PLoS One 7: e33976.

39. Artavanis-Tsakonas S, Rand MD, Lake RJ (1999) Notch signaling: cell fate control and signal integration in development. Science 284: 770-776.

40. Leong KG, Karsan A (2006) Recent insights into the role of Notch signaling in tumorigenesis. Blood 107: 2223-2233.

41. Pannuti A, Foreman K, Rizzo P, Osipo C, Golde T, et al. (2010) Targeting Notch to target cancer stem cells. Clin Cancer Res 16: 3141-3152.

42. Reedijk M, Odorcic S, Chang L, Zhang H, Miller N, et al. (2005) High-leve coexpression of JAG1 and NOTCH1 is observed in human breast cancer and is associated with poor overall survival. Cancer Res 65: 8530-8537.

43. Farnie G, Clarke RB, Spence K, Pinnock N, Brennan K, et al. (2007) Nove cell culture technique for primary ductal carcinoma in situ: role of Notch and epidermal growth factor receptor signaling pathways. J Natl Cancer Inst 99: 616-627.

44. Kopan R, llagan MX (2009) The canonical Notch signaling pathway: unfolding the activation mechanism. Cell 137: 216-233.

45. van Es JH, van Gijn ME, Riccio O, van den Born M, Vooijs M, et al. (2005) Notch/gamma-secretase inhibition turns proliferative cells in intestinal crypts and adenomas into goblet cells. Nature 435: 959-963.

46. Li L, Neaves WB (2006) Normal stem cells and cancer stem cells: the niche matters. Cancer Res 66: 4553-4557.

47. Wicha MS, Liu S, Dontu G (2006) Cancer stem cells: an old idea--a paradigm shift. Cancer Res 66: 1883-1890.

48. Borovski T, De Sousa EMF, Vermeulen L, Medema JP (2011) Cancer stem cell niche: the place to be. Cancer Res 71: 634-639.

49. Velasco-Velazquez MA, Popov VM, Lisanti MP, Pestell RG (2011) The role of breast cancer stem cells in metastasis and therapeutic implications. Am J Pathol 179: 2-11

50. Bourguignon LY, Peyrollier K, Xia W, Gilad E (2008) Hyaluronan-CD44 interaction activates stem cell marker Nanog, Stat-3-mediated MDR1 gene expression, and ankyrin-regulated multidrug efflux in breast and ovarian tumo cells. J Biol Chem 283: 17635-17651.

51. Palyi-Krekk Z, Barok M, Isola J, Tammi M, Szollosi J, et al. (2007) Hyaluronaninduced masking of ErbB2 and CD44-enhanced trastuzumab internalisation in trastuzumab resistant breast cancer. Eur J Cancer 43: 2423-2433. 
Citation: Amador-Molina A, Pérez-Tapia SM, Velasco-Velázquez MA (2012) Therapeutic Targets in Breast Cancer Stem Cells. J Mol Biomarkers Diagn S8:005. doi:10.4172/2155-9929.S8-005

52. Rondon I (2004) (EN) CD44-BINDING LIGANDS, (FR) LIGANDS LIANT CD44 Dyax Corp. Patent WO/2004/024750.

53. Cariati M, Naderi A, Brown JP, Smalley MJ, Pinder SE, et al. (2008) Alpha-6 integrin is necessary for the tumourigenicity of a stem cell-like subpopulation within the MCF7 breast cancer cell line. Int J Cancer 122: 298-304.

54. Wu K, Katiyar S, Li A, Liu M, Ju X, et al. (2008) Dachshund inhibits oncogeneinduced breast cancer cellular migration and invasion through suppression of interleukin-8. Proc Natl Acad Sci U S A 105: 6924-6929.

55. Karnoub AE, Dash AB, Vo AP, Sullivan A, Brooks MW, et al. (2007) Mesenchymal stem cells within tumour stroma promote breast cancer metastasis. Nature 449: 557-563.

56. Ginestier C, Liu S, Diebel ME, Korkaya H, Luo M, et al. (2010) CXCR1 blockade selectively targets human breast cancer stem cells in vitro and in xenografts. J Clin Invest 120: 485-497.

57. Gupta PB, Onder TT, Jiang G, Tao K, Kuperwasser C, et al. (2009) Identification of selective inhibitors of cancer stem cells by high-throughput screening. Cell 138: $645-659$.

58. Zhi QM, Chen XH, Ji J, Zhang JN, Li JF, et al. (2011) Salinomycin can effectively kill ALDH(high) stem-like cells on gastric cancer. Biomed Pharmacother 65: 509-515.

59. Oak PS, Kopp F, Thakur C, Ellwart JW, Rapp UR, et al. (2012) Combinatorial treatment of mammospheres with trastuzumab and salinomycin efficiently targets HER2-positive cancer cells and cancer stem cells. Int J Cancer.

60. Fuchs D, Heinold A, Opelz G, Daniel V, Naujokat C (2009) Salinomycin induces apoptosis and overcomes apoptosis resistance in human cancer cells. Biochem Biophys Res Commun 390: 743-749.

61. Fuchs D, Daniel V, Sadeghi M, Opelz G, Naujokat C (2010) Salinomycin overcomes $A B C$ transporter-mediated multidrug and apoptosis resistance in human leukemia stem cell-like KG-1a cells. Biochem Biophys Res Commun 394: 1098-1104.

62. Kim JH, Yoo HI, Kang HS, Ro J, Yoon S (2012) Salinomycin sensitizes antimitotic drugs-treated cancer cells by increasing apoptosis via the prevention of $\mathrm{G} 2$ arrest. Biochem Biophys Res Commun 418: 98-103.

63. Riccioni R, Dupuis ML, Bernabei M, Petrucci E, Pasquini L, et al. (2010) The cancer stem cell selective inhibitor salinomycin is a p-glycoprotein inhibitor. Blood Cells Mol Dis 45: 86-92.

64. Hirsch HA, lliopoulos D, Tsichlis PN, Struhl K (2009) Metformin selectively targets cancer stem cells, and acts together with chemotherapy to block tumor growth and prolong remission. Cancer Res 69: 7507-7511.

65. Song CW, Lee H, Dings RP, Williams B, Powers J, et al. (2012) Metformin kills and radiosensitizes cancer cells and preferentially kills cancer stem cells. Sci Rep 2: 362.

66. Vazquez-Martin A, Oliveras-Ferraros C, Del Barco S, Martin-Castillo B Menendez JA (2011) The anti-diabetic drug metformin suppresses self-renewal and proliferation of trastuzumab-resistant tumor-initiating breast cancer stem cells. Breast Cancer Res Treat 126: 355-364.

67. Zakikhani M, Dowling R, Fantus IG, Sonenberg N, Pollak M (2006) Metformin is an AMP kinase-dependent growth inhibitor for breast cancer cells. Cancer Res 66: 10269-10273.

68. Memmott RM, Mercado JR, Maier CR, Kawabata S, Fox SD, et al. (2010) Metformin prevents tobacco carcinogen--induced lung tumorigenesis. Cancer Prev Res (Phila) 3: 1066-1076.

69. Micic D, Cvijovic G, Trajkovic V, Duntas LH, Polovina S (2011) Metformin: its emerging role in oncology. Hormones (Athens) 10: 5-15.
This article was originally published in a special issue, Potential Biomarkers and Therapeutic Targets in Cancer Stem Cells handled by Editor(s). Dr. Murielle Mimeault, University of Nebraska Medical Center, USA 